\title{
THERAPEUTIC EFFECTS OF PINOCEMBRIN ON INDOMETHACIN-INDUCED GASTRIC ULCER MODEL IN RATS BY
}

Ayatallah Ali Eldemerdash Saad, Mariane G. Tadros*, Doaa A. Elsherbiny *, Esther T. Menze

FROM

*Police Academy, General Department of Medical Services, ministry of Interior.

* Department of Pharmacology and Toxicology, Faculty of Pharmacy, Ain Shams University, Cairo, Egypt.

\begin{abstract}
Indomethacin considered one of the most commonly used NSAIDs to treat pain and inflammation among elder patients. Ironically, it has high risk of gastrointestinal complication, ulceration and in some cases perforation. Pinocembrin is one of the natural flavonoid present in honey and posses anti-inflammatory, anti-oxidant, and antiapoptotic activities. The present study was conducted to investigate the possible therapeutic effects of Pinocembrin on indomethacin induced gastric ulcer model in rats. Animals either pre-treated with pinocembrin $50 \mathrm{mg} / \mathrm{kg}$ for 3 days before ulcer induction with one single dose of indomethacin $(48 \mathrm{mg} / \mathrm{kg}$ ) orally or post-treated with pinocembrin $50 \mathrm{mg} / \mathrm{kg} / 3$ days and $50 \mathrm{mg} / \mathrm{kg} / 5$ days after $1 \mathrm{hr}$ of ulcer induction with same dose of indomethacin. The therapeutic effects were determined via measuring oxidative stress markers as well as histopathological investigation. Pinocembrin protected gastric tissues which was confirmed histopathologically. It also increased levels of CAT, GSH and decreased levels of MDA enzymes. In conclusion, these findings show that pinocembrin have therapeutic effects in indomethacin induced gastric ulcer.
\end{abstract}

\section{Introduction}

In the digestive system, peptic ulcer denote one of the most critical diseases which caused by disturbance in the protection of stomach mucosa against gastric acid (Bucciarelli et al., 2010; Sa'nchez-Mendoza et al., 2011). Nowadays the risk of gastric attacks is significantly increased due to exposure of human to many noxious agents such as alcohol consumption, Heliobacter pylori infection and use of nonsteroidal anti-inflammatory drugs (NSAIDs) and it is estimated that nearly $20 \%$ of the world population suffer from peptic ulcer (Laine et al., 2008; Shalini and Rajan .,2015).

Indomethacin is one of NSAIDs that has been shown to cause inflammation through the generation of reactive oxygen species (ROS) that seem to play an important role in generating lipid peroxides (Kwiecien et al., 2002; Laine et al., 2008). Even though many synthetic drugs are available in the clinical practice, the researchers still in search of antiulcer compounds from natural resources with higher efficacy and lower side effects (Bandyopadhyay et al., 2002; Bucciarelli et al., 2010). 
Pinocembrin (5,7-dihydroxyflavanone) is one of the primary flavonoids that has been identified in honey and has been studied in many diseases such as stroke, Alzheimer, cardiovascular, and atherosclerosis in vitro and in vivo (Lan et al., 2015).

In an in vitro study, (Soromou et al.,2012) demonstrated that pinocembrin inhibits proinflammatory cytokines in the murine macrophage and endotoxin-induced acute lung injury model, partly by decreasing the levels of MAPK and NF- $\kappa \mathrm{B}$ activation. In vivo, pretreatment with pinocembrin $(50 \mathrm{mg} / \mathrm{kg}$, IP) significantly lowered LPS-induced pro-inflammatory cytokines TNF- $\alpha$, IL-1 $\beta$ and IL-6 production in a time-dependent manner, indicating that the protective role may be attributable, to inhibition of pro-inflammatory cytokine release. (Soromou et al., 2014) also found that pretreatment with pinocembrin $(20$ or $50 \mathrm{mg} / \mathrm{kg}$, IP) reduced mortality from LPSinduced endotoxin shock in mice, however, post-treatment with pinocembrin failed to exert any therapeutic effects.

The aim of this study were to evalute the potential Therapeutic effects of Pinocembrin on indomethacin induced gastric ulcer model in rats and the possible underlying mechanisms through studying the anti-inflammatory, and anti-oxidant properties.

\section{Material and methods}

\section{Material}

Pinocembrin (PIN) was purchased from Xi'an natural-field bio-technique Co, Shanghai, China. Indomethacin (IND) was purchased from Nile Co. for Pharmaceutical and Chemical Industries, Egypt. Used chemicals were obtained from Indomedix Co., and Sigma pharmaceutical industries Cairo, Egypt. All chemicals were of the highest purity grade commercially available.

\section{Animals}

Male spargue-Dawly rats (180-200 gm) were obtained from Nile Co. for Pharmaceutical and Chemical Industries, Cairo, Egypt. Animals were provided with balanced laboratory diet and tap water ad libitum for 1 week before assignment to the experimental protocol. All animals were deprived of food $24 \mathrm{hr}$ before ulcer induction with free access to tap water. Experimental procedures were conducted in accordance with the international ethical guidelines for investigations in laboratory animals and were approved by the Research Ethical Committee of Faculty of Pharmacy, Ain shams University (Cairo, Egypt).

\section{Method \\ Experimental design}

Animals were randomly divided into five groups (six animals each). The first group received the vehicle only and served as the control group. The second group received single oral dose of IND $48 \mathrm{mg} / \mathrm{kg}$ (Krishnendu et al., 2015), to induce gastric ulcer. The third was given pinocembrin $50 \mathrm{mg} / \mathrm{kg} / \mathrm{day}$, for 3 days perior to ulcer induction. The fourth and fifth groups were given pinocembrin $50 \mathrm{mg} / \mathrm{kg} / \mathrm{day}$, for 3 consecutive days and 5 days respectively $1 \mathrm{hr}$ after ulcer induction. Pinocembrin doses were determined based on previous studies reporting its properties (Lan et al., 2015). Rats were sacrificed 6 hrs later and stomach tissues were dissected out, and washed with ice-cold saline. Gastric tissue specimens of each group were fixed in $10 \%$ formalin for histopathological examination. 


\section{Assessment of oxidative stress markers}

Catalase enzyme (CAT), reduced glutathione (GSH) and malondialdehyde (MDA) levels were determined colorimetrically by using Biodiagnostics kits (Cairo, Egypt). All procedures were performed according to the manufacturer's instructions.

\section{Histopathological \& mucin content examination}

Stomach sections from different groups were sliced and fixed in $10 \%$ formalin then, embedded in paraffin blocks. Slices of $4 \mu \mathrm{m}$ thickness were stained with either hematoxylin \& eosin (H\&E) stain in case of histopathological examination, or alcian blue stain for mucin detection using light microscope (Bancroft et al, 1996).

\section{Statistical analysis}

Data are presented as mean \pm SD. Multiple comparisons were performed using one-way ANOVA followed by Tukey-Kramer test for post hoc analysis. All statistical analyses were performed, while the graphs were drawn using a prism computer program (GraphPad software Inc., La Jolla, CA, USA) with p value less than or equal to 0.05 represent statistical significance.

\section{Results}

\section{oxidative stress markers.}

\section{CAT assessment:}

Catalase levels were significantly reduced in indomethacin treated group by $38.6 \%$ as compared to control values. Interestingly, pinocembrin $50 \mathrm{mg} / \mathrm{kg}$ pretreatment significantly increased CAT level by $85.4 \%$ as compared to $80.8 \%$ increase in case of pinocembrin $50 \mathrm{mg} / \mathrm{kg} / 3$ days treated group. pinocembrin $50 \mathrm{mg} / \mathrm{kg} / 5$ days showed $93.7 \%$ increase in CAT level. The longest duration of pinocembrin treatment $(50 \mathrm{mg} / \mathrm{kg} / 5$ day) showed the best antioxidant effect when compared to groups.(Fig.1)

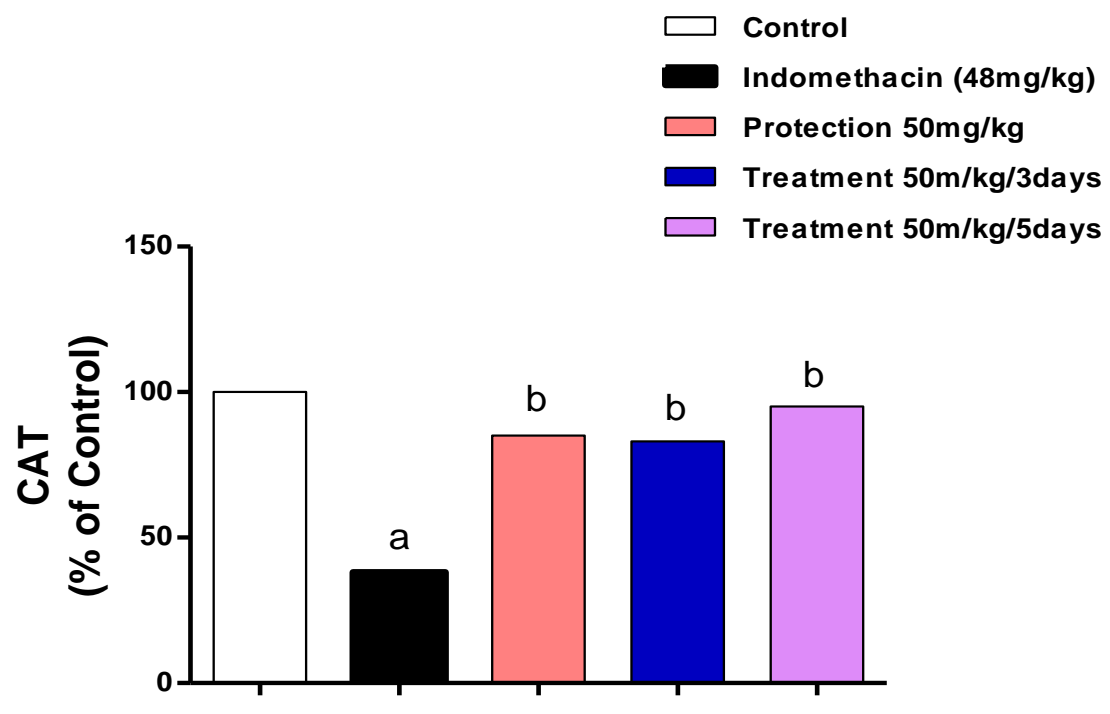

Fig. (1): Effect of pinocembrin on gastric tissue level of catalase enzyme (CAT) in indomethacin-induced gastric ulcer model as percentage of control. a or b:

Statistically significant from the control or the indomethacin group, respectively at $\mathrm{P}<$ 0.05 using ANOVA followed by Tukey-Kramer as a post-hoc test. 


\section{GSH assessment:}

GSH level was markedly decreased in indomethacin treated rats by $40.2 \%$ as compared to control values. Rats pretreated with pinocembrin $50 \mathrm{mg} / \mathrm{kg}$ significantly decreased GSH level by $89.4 \%$ as compared to $91.3 \%$ increase in case of pinocembrin $50 \mathrm{mg} / \mathrm{kg} / 3$ days treated group. pinocembrin $50 \mathrm{mg} / \mathrm{kg} / 5$ days showed $95.1 \%$ increase in GSH level.(Fig.2)

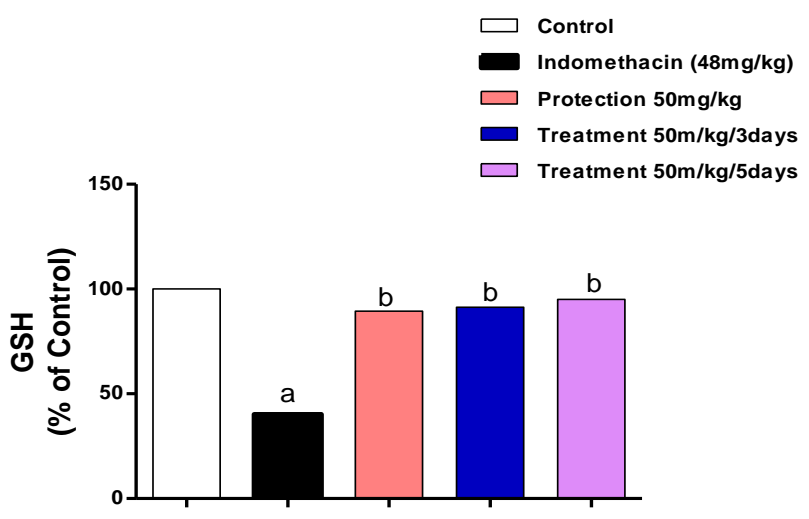

Fig. (2): Effect of pinocembrin on gastric tissue level of reduced glutathione (GSH) in indomethacin-induced gastric ulcer model as percentage of control. a or b:

Statistically significant from the control or the indomethacin group, respectively at $\mathrm{P}<$ 0.05 using ANOVA followed by Tukey-Kramer as a post-hoc test.

\section{MDA assessment:}

MDA level was markedly increased in indomethacin treated rats by $187.5 \%$ compared to control values. Rats pretreated with pinocembrin $50 \mathrm{mg} / \mathrm{kg}$ significantly decreased MDA level by $114.3 \%$ as compared to $85.2 \%$ increase in case of pinocembrin $50 \mathrm{mg} / \mathrm{kg} / 3$ days treated group. pinocembrin $50 \mathrm{mg} / \mathrm{kg} / 5$ days showed $92.6 \%$ increase in MDA level. (Fig.3)

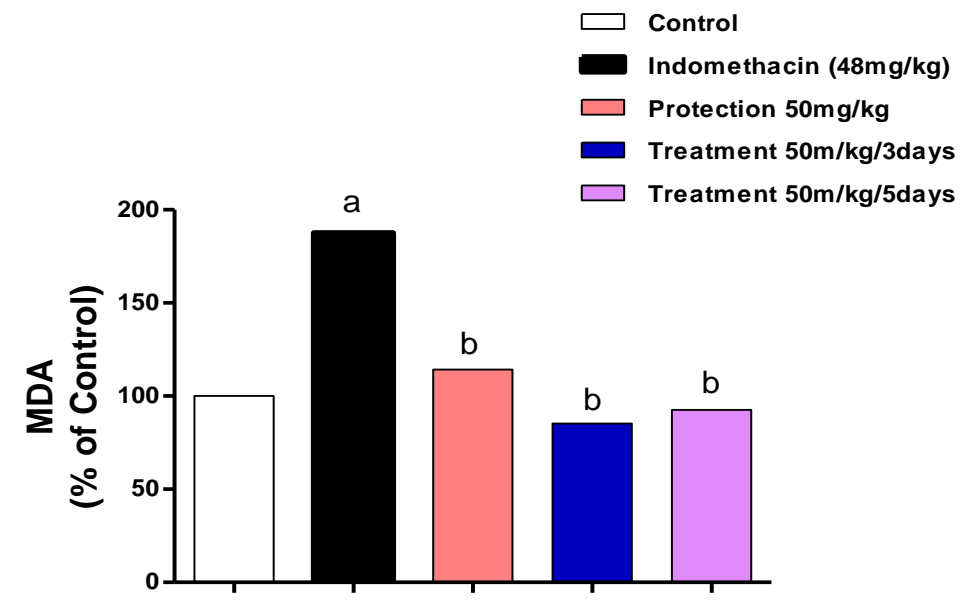

Fig. (3): Effect of pinocembrin on gastric tissue level of malondialdehyde in indomethacin-induced gastric ulcer model as percentage of control. $a$ or $b$ :

Statistically significant from the control or the indomethacin group, respectively at $\mathrm{P}<$ 0.05 using ANOVA followed by Tukey-Kramer as a post-hoc test. 


\section{Histopathology}

Figure 4 shows the effects of the different treatment groups on the histological structure of stomach. No histopathological alterations were recorded in the control group (Fig. 4A). Focal ulceration and pigmentation of the tips of the mucosa were detected associated with massive numbers of inflammatory cells infiltration and congestion in the blood of the submucosa in gastric tissues taken from indomethacin-treated group (Fig. 4B). Animals pretreated by pinocembrin $50 \mathrm{mg} / \mathrm{kg} / 3$ days showed no histopathological alternation (Fig. 4C). Gastric tissues in pinocembrin $50 \mathrm{mg} / \mathrm{kg} / 3$ days treated group showed blood congestion in the submucosa (Fig. 4D). Animals treated with pinocembrin $50 \mathrm{mg} / \mathrm{kg}$ for 5 days showed no histopathological change (Fig. 4E).
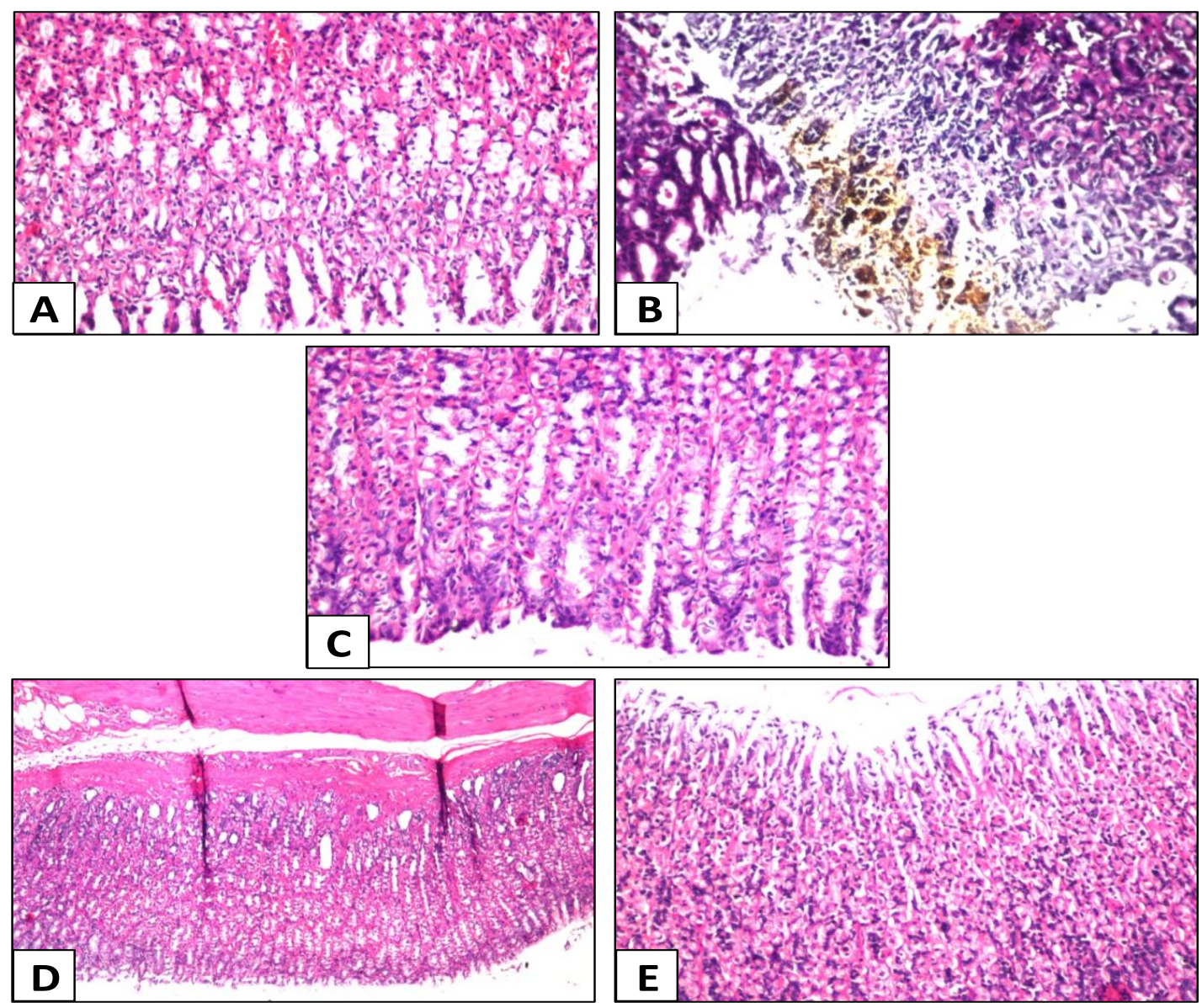

Fig. (4): Effect of pinocembrin treatment on indomethacin induced histological alternation of gastric tissue. Photomicrographs of haematoxylin and eosin stained stomach sections from different groups: A: Section from control group shows normal gastric tissue structure $(\times 40)$. B: Section from indomethacin-treated group shows Focal ulceration and pigmentation of the mucosa associated with massive numbers of inflammatory cells infiltration and blood congestion in the submucosa $(\times 40)$. C: Section from pinocembrin $50 \mathrm{mg} / \mathrm{kg}$ pre-treated showing no histopathological alternations $(\times 40)$. D: Section from pinocembrin $50 \mathrm{mg} / \mathrm{kg} / 3$ days treated group showing blood congestion in the submucosa (x16). E: Section from pinocembrin $50 \mathrm{mg} / \mathrm{kg}$ treated group for 5 days showing no histopathological alternations $(\times 40)$. 


\section{Mucin content}

Photomicrographs from control group (Fig. 5A) showed alcian blue moderate positive reaction with mucin appeared as blue color in mucosal layer while indomethacin-treated group showed alcian blue negative reaction in the area of ulceration of the mucosa (Fig. 5B). All other groups showed alcian blue severe positive reaction in mucosal layer (Fig.5C\&5D) except pinocembrin $50 \mathrm{mg} / \mathrm{kg} / 5$ days posttreated group (Fig. 5E) which showed moderate reaction with alcian blue in mucosal layer. (Fig. 5)
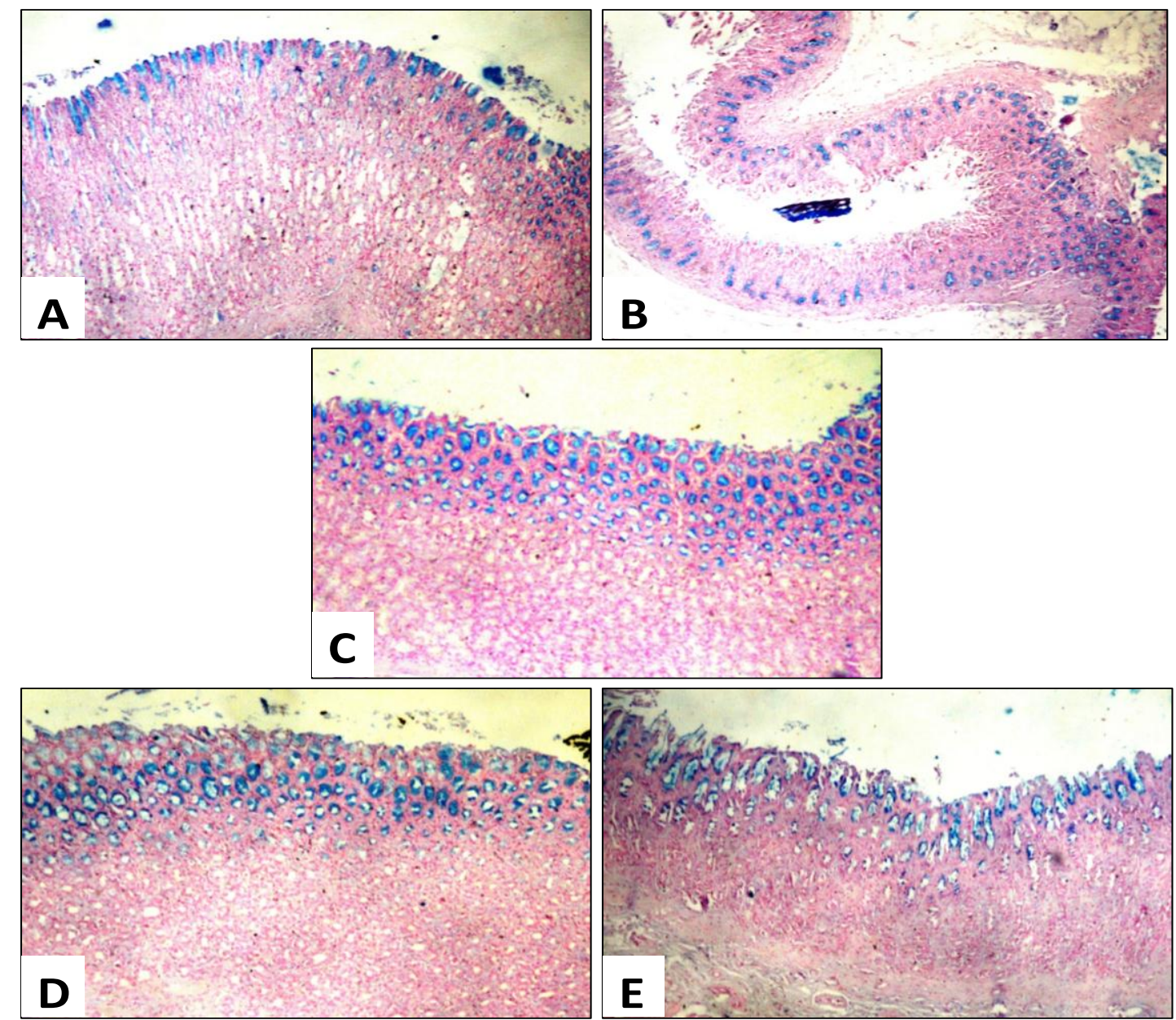

Fig. (5): The severity of Alcian Blue Mucopolysaccharide detection in mucosal layer of stomach in different experimental groups. Control group (A) showed moderate reaction $(++)$ while indomethacin treated group (B) showed mild reaction which indicate reduced mucin secretion $(+)$. Pinocembrin $50 \mathrm{mg} / \mathrm{kg}$ pretreated group and pinocembrin $50 \mathrm{mg} / \mathrm{kg} / 3$ days post-treated group (C and D) respectively, showed sever reaction(+++) while pinocembrin $50 \mathrm{mg} / \mathrm{kg} / 5$ days post-treated group (E) showed moderate alcian blue reaction $(++)$ in mucosal layer.

\section{Discussion}

Gastric ulcer therapy nowadays represent one of the challenges facing medicine since currently marketed drugs showed limited efficacy and severe side effects (Mota et al., 2009). Therefore, the development of anti-ulcer compound from natural resources is still a target in recent medicinal research. The present study was designed to investigate 
the potential therapeutic effects of pinocembrin on indomethacin-induced gastric ulcer in rats as well as the possible underlying mechanisms through studying the antiinflammatory, and anti-oxidant properties.

It showed that administration of pinocembrin $50 \mathrm{mg} / \mathrm{kg}$ for 3 days prior to ulcer induction protected the stomach from the damage caused by indomethacin which was confirmed by histopathological assessment and oxidative stress markers determination. The histopathological findings demonstrated that the administration of pinocembrin $50 \mathrm{mg} / \mathrm{kg}$ for 5 days after ulcer induction showed complete healing effect on gastric tissue which was further confirmed by mucin content assessment. Treatment with same dose of pinocembrin for 3 days showed blood congestion in submucosa with intact mucosa which was confirmed by severe reaction with alcian blue stain in the mucosal layer . Pinocembrin also induced antioxidant effects, it increased gastric tissue levels of catalase, reduced glutathione and decreased levels of malondialdehyde in a time dependent manner. This was in line with previous studies concerning pinocembrin antiinflammatory, and anti-oxidant properties (Lan et al, 2015). Pinocembrin's pharmacological activities has been well investigated, for its anti-inflammatory, antiapoptotic, antioxidant and anticancer effects especially in Alzheimer's disease, cardiovascular diseases, and atherosclerosis. Studies showed that pinocembrin (10 $\mathrm{mg} / \mathrm{kg}$, i.v.) could reduce brain swelling; and alleviate neuronal apoptosis (Gao et al.,2008, Lan et al., 2015).

In summary, the present study demonstrated that pre-treatment with pinocembrin showed a protective capacity and markedly attenuated indomethacininduced oxidative stress and gastric tissue damage. pinocembrin post-treatment showed antioxidant activity which was increased in time dependent manner. This was evident by the significant increase in CAT, and GSH levels and decrease in MDA level in gastric tissue samples of both treatment groups as compared to indomethacin-treated group. The previous results suggest that pinocembrin might represent a promising pharmacological drug in gastric ulcer treatment with potential antioxidant and antiinflammatory properties.

\section{Conclusion}

In conclusion, the present study provides an evidence for the therapeutic effects of pinocembrin on indomethacin-induced gastric ulcer in which it acts as gastroprotective agent prior to ulcer or as a treatment after ulcer induction. Further studies may be done to determine the optimum therapeutic dose of pinocembrin which poses the highest effect and the lowest side effects .

\section{REFERENCES:}

Banchroft,J.D., Stevens, A. and Turner, D.R., 1996. Theory and Practice of Histological Techniques. Fourth Edition, p. 25. Churchil Livingstone, New York.

Bandyopadhyay D., Biswas K., Bhattacharyya M., Reiter RJ., Banerjee RK., 2002. Involvement of reactive oxygen species in gastric ulceration: protection by melatonin. Ind J Exp Biol; 40:693-705.

Bucciarelli, A., Minetti, A., Milczakowskyg, C., Skliar, M., 2010. Evaluation of gastroprotective activity and acute toxicity of Solidago chilensis Meyen (Asteraceae). Pharmaceutical Biology 48, 1025-1030. 
Gao M, Liu R, Zhu SY, Du GH,. 2008. Acute neurovascular unit protective action of pinocembrin against permanent cerebral ischemia in rats. J Asian Nat Prod Res 10(5-6):551-558.

Krishnendu,S.,Pritam, S., Sukanya, S., Pabitra, P., Pamames, C.,2015. Morin protects gastric mucosa from nonsteroidal anti-inflammatory drug, indomethacin induced inflammatory damage and apoptosis by modulating NFкb pathway. Biochimica et Biophysica Acta.1850: 769-783.

Kwiecien S, Brzozowski T, Konturek S.J., 2002. Effects of reactive oxygen species action on gastric mucosa in various models of mucosal injury Journal of Physiology Pharmacology, 53, pp. 39-50.

Laine L, Takeuchi K, Tarnawski A., 2008. Gastric mucosal defense and cytoprotection: bench to bedside. Gastroenterology 135: 41-60.

Lan, X.; Wang, W.; Li, Q.; Wang, J., 2015. The Natural Flavonoid Pinocembrin: Molecular Targets and Potential Therapeutic Applications. Mol Neurobiol.doi:10.1007/s12035-015-9125-2.

Mota KSL., Dias GEN., Pinto MEF., Luiz-Ferreira A., Souza-Brito AR., HirumaLima CA., et al., 2009. Flavonioids with gastroprotective activity.14: 9791012.

Sa'nchez-Mendoza, M.E., Reyes-Ramsrez, A., Cruz Antonio, L., Martnez Jiménez, L., Rodrguez-Silverio, J., Arrieta, J., 2011. Bioassay-guided isolation of an antiulcer compound, Tagitinin C, from Tithonia diversifolia: role of nitric oxide, prostaglandins and sulfhydryls. Molecules 16, 665-674.

Shalini R, Rajan S., 2015. Antiulcer activity of Hemidesmus indicus root on ethanol$\mathrm{HCl}$ induced ulcer in rats. Indo Am J Pharm Res, 5(05):1995- 2001,.

Soromou LW, Chu X, Jiang L, Wei M, Huo M, Chen N, Guan S, Yang X et al., 2012. In vitro and in vivo protection provided by pinocembrin against lipopolysaccharide induced inflammatory responses. Int Immunopharmacol 14(1):66-74. doi:10.1016/j.

Soromou LW, Jiang L, Wei M, Chen N, Huo M, Chu X, Zhong W, Wu Q et al., 2014. Protection of mice against lipopolysaccharide induced endotoxic shock by pinocembrin is correlated with regulation of cytokine secretion. J Immunotoxicol 11(1):56-61. doi:10. 3109/1547691X.2013.792886. 


\section{دراسة التأثيرات العلاجية للبينوسمبرين على نموذج قرحة المعدة المحدث بالاندوميثاسين في الجرذان}

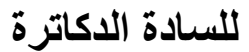

اية الله على الدمر اش- ماريان جورج تادروس* ـ دعاء احمد مختار الثربينى_استر ثروت منز

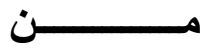

اكاديمية الثرطة، الادارة العامة للخدمات الطبية بوزارة الداخلية

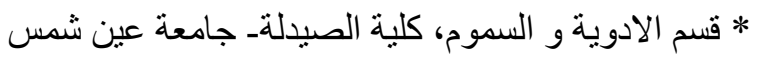

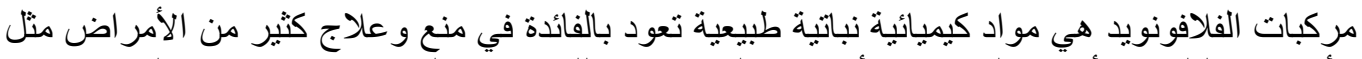

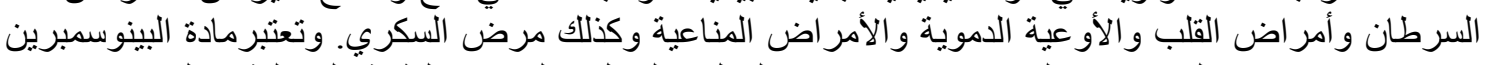

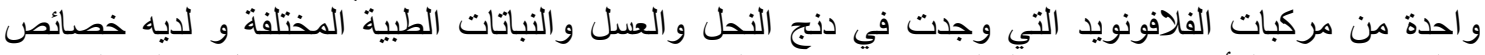

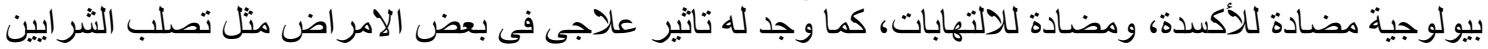

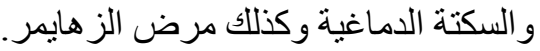

تهدف الدراسة الحالية الي تقييم التأثيرات العلاجية للبينوسمبرين على نموذج قرحة المبر المعدة المحدث

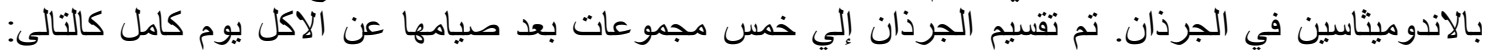

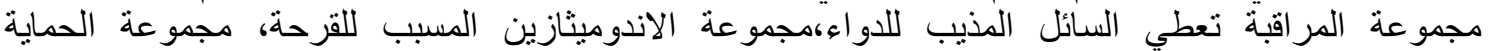

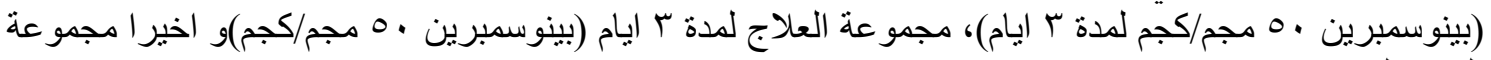

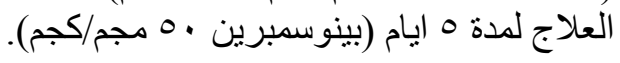

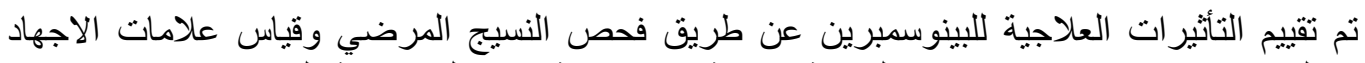

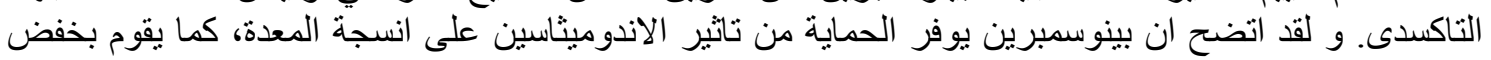

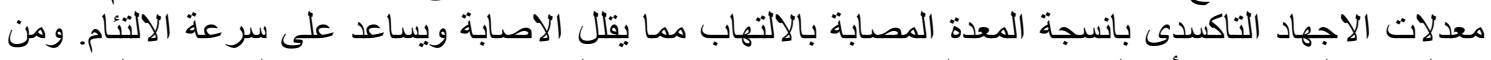

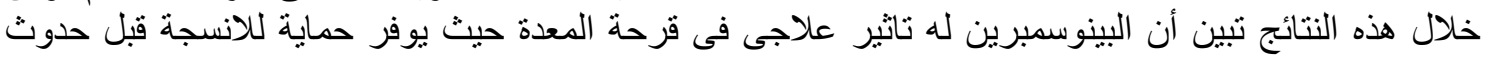

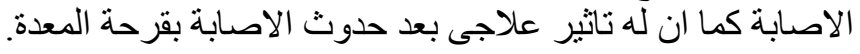

